International Journal of English Literature and Social Sciences
Vol-6, Issue-2; Mar-Apr, 2021
Journal Home Page Available: https://ijels.com/
Journal DOI: $10.22161 /$ ijels

\title{
Investigating the Process of Learning and Relationship Building on the Social Media
}

\author{
Siyu Chen
}

Department of Humanities, Meisei University, Japan

Received: 28 Nov 2020; Received in revised form: 03 Feb 2021; Accepted: 18 Feb 2021; Available online: 11 Mar 2021

(C)2021 The Author(s). Published by Infogain Publication. This is an open access article under the CC BY license

(https://creativecommons.org/licenses/by/4.0/).

\begin{abstract}
Technology which plays a crucial role on balancing human actors and non-human actors provides a public platform for people to socialize and learn across time and space in the process of information sharing. The purpose of this research is to see the practice of learning on the social media. Besides, through collaboration, relationship building is also crucial in social learning process. In order to facilitate learning, people also tend to use some strategies to establish and maintain the relations. In this case, learning and relationship construction couldn't be separated in the process of knowledge construction. Thus, this research explores the social learning process on the Social Networking Service (SNS) from the following two perspectives, learning perspective and the social relation perspective. The purpose of this research is to answer the following questions:
\end{abstract}

What and how can people learn through social media?

How are social relations constructed on the social media?

My research data mainly includes online chatting and qualitative interviews, collected from two SNS applications which are" Sina Weibo" and "Hellotalk". The data represents communication among people from diverse backgrounds, reflecting interaction particularly between my participants and me, and with others. In this study, I explore the learning process on the social media and the relationship construction at a micro level utilizing qualitative methods. Theoretically, this research adds knowledge to our understanding of social behavior online in general and of the process of learning and social relationship building on the social media in particular. Methodologically, I also provide a qualitative micro level model for the analysis of such social practice.

Keywords - learning, relationship construction, technology, human and non-human factors.

\section{INTRODUCTION}

The learning habits are changing and greatly influenced by technology in the digital age. When people come across difficulty in daily life, the Internet becomes the nearest resources for them to locate and search for information. To some extent, social media enhances the process of learning. First, people are not restrained by time and space anymore. They could look for any information online whenever they like. Second, social media tools are providing the opportunities for the learners to enhance multiliteracy and the abilities of interaction. People can discover the endless amount of information and resources in cyberspace.
Besides, not just information and resources, there are many active people on the social media platforms exchanging, sharing and updating the knowledge and information. Most of people prefer to be engaged in interactions aiming at problem solving and the things which they are interested in. As Vygotsky (1978) pointed out that knowledge is constructed through the process of knowledge sharing and social interaction. On the social media platform, there are more knowledgeable people who share new ideas or insights with their expert knowledge and personal experience. Importantly, people are involved in the social interactions in the learning process, which also leads to 
relationship construction. Especially in the virtual space, the maintenance of interaction among people is considered crucial. Thus, relationship building is essential in the learning process. The need-to-belong theory, proposed by Baumeister and Leary (1995), explains the function of the motivation and commitment to maintain the continuous interaction and social bonds in the learning process. Thus, it can be seen that the features of technology facilitate the process of learning and enhance the engagement of knowledge sharing, participation and social interactions among people. In this study, I explore the learning process on the social media and the relationship construction at a micro level utilizing qualitative methods.

\section{WEIBO AS A PLATFORM FOR LEARNING}

I interpret data collected on the Weibo platform, which reveals communication among the people who I got to know due to the same illness, tinnitus. My data includes screen shot of actual online communication as well as interview afterwards. The participants include $\mathrm{C}$ and $\mathrm{N}$ in this study. Firstly, Actor-Network Theory (ANT) adds a perspective to examine how learning takes place when human and nonhuman factors assemble together. In addition, the three key concepts of communication visibility, metaknowledge, and transactive memory also help me to analyze the online learning process.

$\mathrm{C}$ and $\mathrm{N}$ are the persons that I encountered on Sina Weibo platform due to the same ear problem, called illness. On Sina Weibo, I observed lots of posts published by different kinds of people. From those posts, I found C's symptom was most similar to mine. Then, I commented under his post and had the continuous interaction with him later. $\mathrm{N}$ found me through C's post. Finally, we three got connected and have interactions.

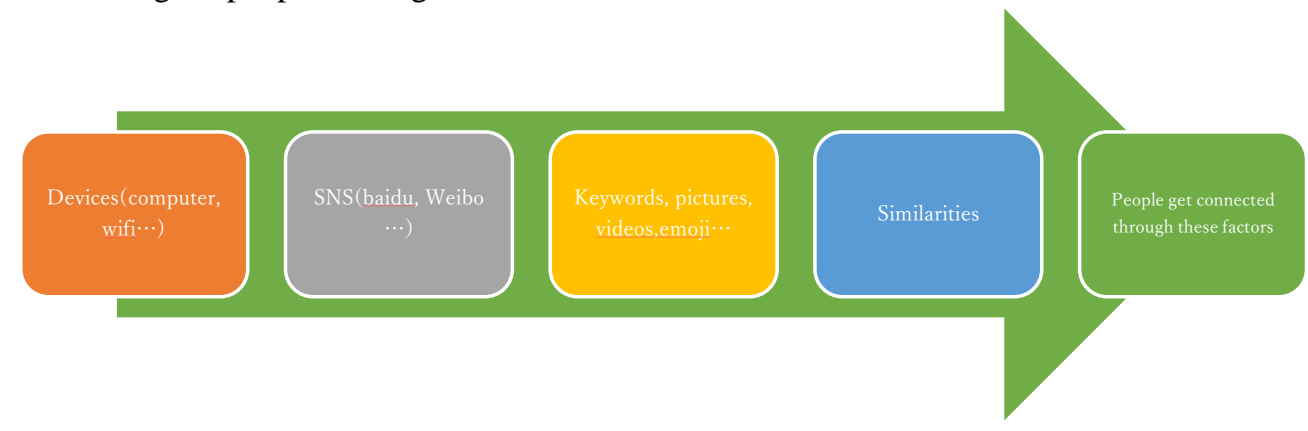

Fig.1: Getting connected on the social media

However, at the beginning, I searched for Baidu, and input the keyword, "tinnitus", then there were lots of detailed descriptions about this illness, such as detailed explanation about the symptoms of tinnitus, recommended medicines, recommended doctors and so on. These information were presented in various forms, such as text and video.

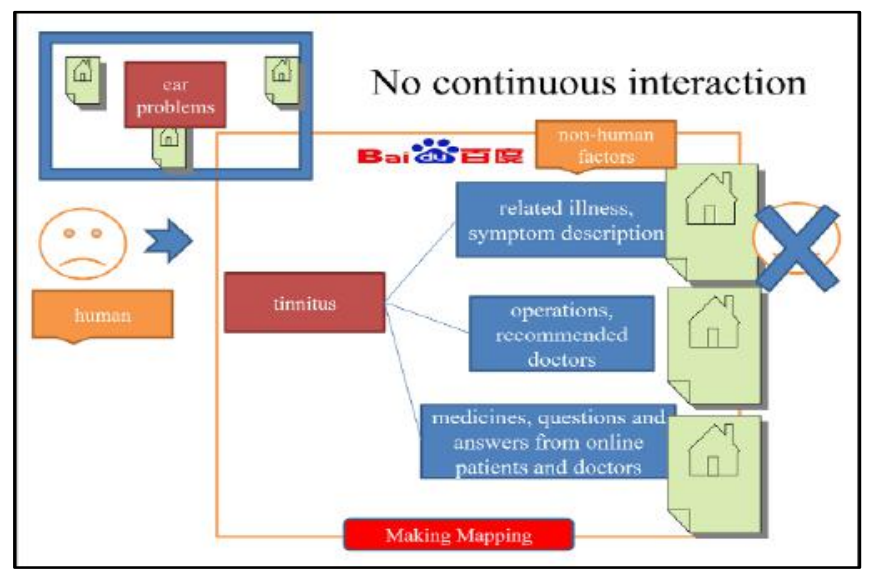

Fig.2: Search result by key word "tinnitus" on Baidu
The Internet, such non-human actor, helped me to locate relevant information. Today, when people encounter problems, the Internet, becomes the nearest information source and it leads people to locate information online. In my case, through inputting the keyword, all the related information appeared. However, even though there are many descriptions and discussions from online patients and doctors, Baidu turns to be a dead end for human interaction and there is very limited feedback and continuous interaction among people. Since there is no human interaction on Baidu, I, thus, turned to another social platform-Sina Weibo.

On Weibo, I also put the keyword, "tinnitus" and upon clicking on the "search" button, I could see thousands of people were sharing their experience with the problem, such as recovery, medicine, the reason why tinnitus happens, and so on. There are some examples of posts shown as below. 


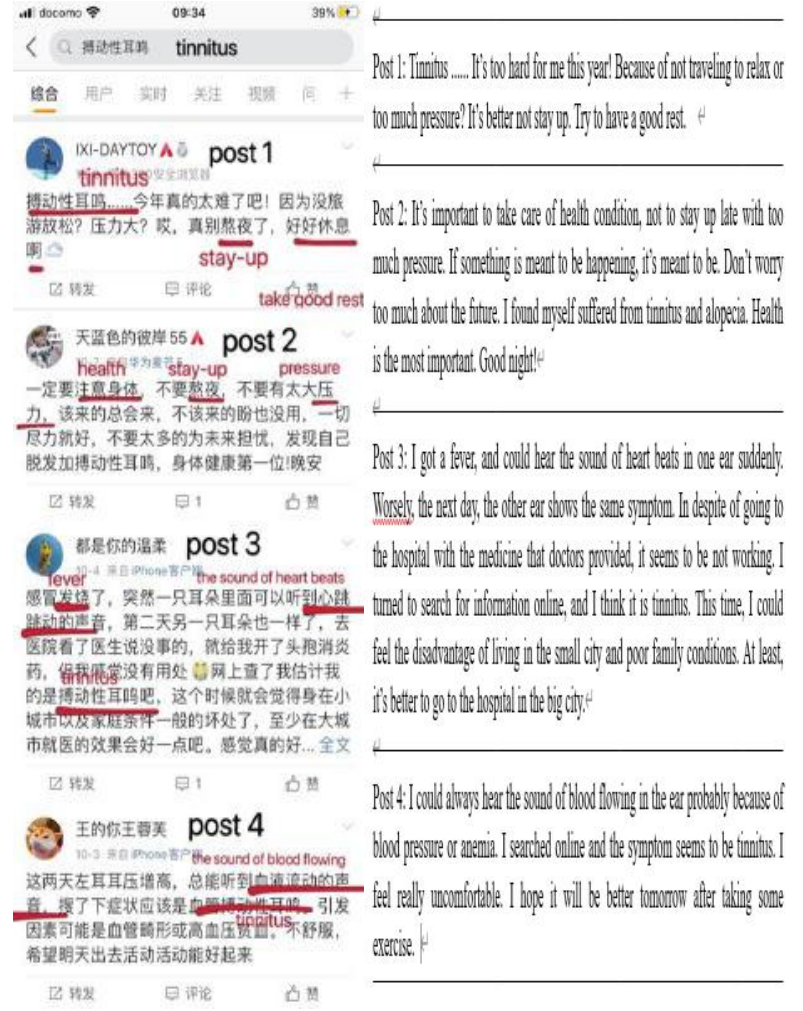

Screen Shot 1 People sharing their experience with tinnitus on Weibo

Upon observing others' posts, I could locate information relating to my situation, then, choose the person who I think C's symptom is similar to me and have the interaction. Leonardi (2014) states that "once invisible communication occurring between others becomes visible for third party, those third parties could improve their metaknowledge. Communication visibility, in this case made possible by the enterprise social networking sites" (p.796). Learning starts from observing the behaviors and experience of others. Social networking sites foster observational learning indeed. "As asserted by social cognitive theorists, human beings have evolved an advanced capacity for observational learning that enables them to advance their knowledge and skills beyond their fields of experience". (Mbati, 2013, p.170). Through observing the visible contents shared by others on Weibo platform, people could develop their current knowledge and skills to solve their problems, which is referred to "metaknowledge". Meta-knowledge is described as the knowledge of who know what and who knows whom (Leonardi, 2014). When people acquire knowledge, they must know where the information could be accessed and who to turn to. And through long-term interaction, people learn from others' personal experience and knowledge, which shows individuals can serve as external memory aids to each other and share useful information to solve the mutual problem. Transactive memory refers to a shared system among people for encoding, storing, and retrieving information (Wegner et al, 1985). Information sharing is an essential in online learning process. In order to solve problems or receive new ideas and knowledge, people will retrieve the information and experience from those external resource and internalize the knowledge into themselves.

From what I presented above, leaning habits are changing in the digital age. Social media provides people with a public platform which allows them to share, diffuse, and exchange information in a transparent environment, which makes communication visible. People in different fields could gather together in the cloud. They could gain the knowledge without time and space restriction. However, not only human actors, but also non-human actors matter in the learning process. The non-human factors have the equal functions with human factors. "Humans are not assumed to have a privileged a priori status in the world but to be part of it" (Fenwick and Edwards, 2010, p.3). Without nonhuman factors, some activities couldn't even happen. As human and non-human assemble together, things start to take effects. Technology, this non-human factor, gathers people together and make associations, breaking up the limitation of time and space. No matter where they are, people could get connected and form relations. Also, internet provides the transparency to all the users on the social media platform. People could observe the contents that others are sharing, updating and exchanging, making the communication visible. By observing the contents, people could select the information they need and find ways to locate information, which could facilitate their metaknowledge. Through long-term interaction, people retrieve the knowledge that is stored in other individual's memory to facilitate their own knowledge. Thus, learning takes place through interactions among people.

In the digital age, the internet becomes the nearest and convenient resources for people to locate information. Poell et al. (2014) regard Weibo platform as participants, examining the particular technological features of Weibo and how this non-human factor and human actors mutually articulate each other. Technology provides a public platform for people to socialize and learn across time and space in the process of information sharing. Through looking for information, non-human factors guide people to select useful information and get connected with the people who have similarities with them. This also reveals the experience $\mathrm{I}$ had with $\mathrm{C}$ and $\mathrm{N}$. 


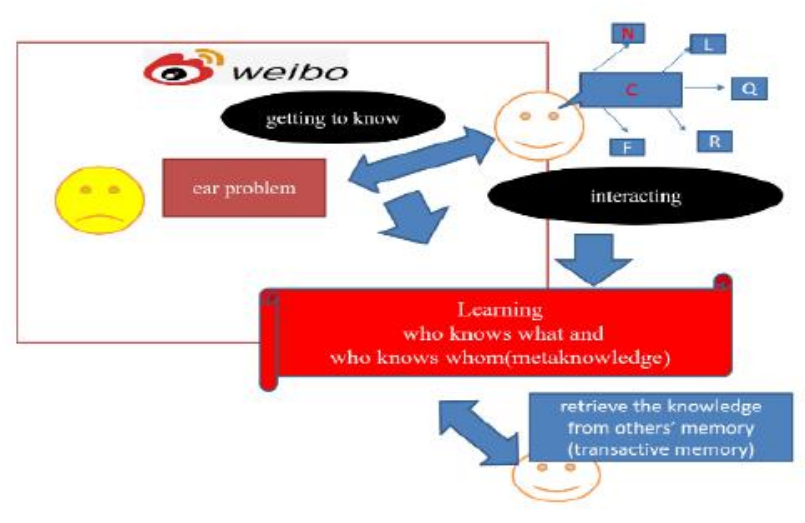

Fig.3: Learning process on the social media

Due to the similar symptom and experience, I got to know $\mathrm{C}$ and through $\mathrm{C}$, I also got connected with the people that $\mathrm{C}$ was connecting to. ANT tries to regard all the things as enactments, connected through relations and connections of both human and non-human factors (Law, 2009). In the process of information-searching, not only human factors, computers. The Internet, keywords, and posts, all such nonhuman factors play an important role in the socializing process. They connect people together across the time and space and form the relations.

\section{RELATIONSHIP BUILDING ON THE SOCIAL MEDIA}

I explore the process of learning on the social media, seeing how learning takes place on the social media. Since learning on the social media cannot be achieved without human relations. I also see the process of social relationship construction online. Need-to-belong theory (Baumeister, 2011) helps me to examine the process of relationship building. As Baumeister (2011) states that the main idea of need to belong is: "people have a fundamental, strong and pervasive motivation to form and maintain at least a certain minimum number of social relationships" (p.124). In my study, the need-to-belong theory helps me to explore how relationship is constructed and enhanced through interaction on the social media.

Below is my interaction with $\mathrm{M}$ whom I got to know through Hellotalk application. $\mathbf{M}$ is from Zambia, an African country, studying in China now. He had told me that because of the skin color, he had been suffered from discrimination, which made him unwilling to make friends with Chinese students in reality, so he turned to social media for socialization. Through our long-time interaction, $\mathbf{M}$ showed special feeling to me and hoped to develop our relationship.

The following is my online interview with $\mathrm{M}$.
Me: Why do you regard me as your friend but not make friends in reality? They treat you bad?

M: 1 . Not everyone is like you, Chen. I don't know. They treat us like we are useless or we are just disgusting. So 2. I just make friends on the phone not in reality.

Me: I am really sorry about this. By the way, Didn't you make friends with others on this app?

\section{M: 3. I know some people here, but I just help them to speak English.}

Me: Do they speak with you in order to learn English?

M: Yeah most of them speak some English.

Me: I'm glad that Chinese students don't treat you well in reality but you still make friends with Chinese on this and trust me. Thank you.

M: Yeah and 4. I made friends especially with you because you have been out of China before. And your outside knowledge of life is more. 知识外, 你的心胸开阔(You are out of China, and you are open-minded). I hope I meet more people like you in reality. I wish I could meet you.

\section{(10.25.2019)}

M suffered from discrimination when he was studying in China. He once told me that Chinese people wouldn't like to make friends with him because of their skin color, even when he took the subway, no one wanted to sit near him and make faces to him. In the underlined part 2, he said he just wanted to make friends on the phone not in reality. He knew that I am Chinese but still wished to make friend with me. In the underlined part 1, M said not everyone is like you, Chen. Later, he explained the reasons why he said so and made friend especially with me. First, the underlined part 3 shows that on this app, most of the people make friends with him in order to improve their English but not would like to make friends with him from the bottom of heart. However, he thought that I made friend with him without that purpose. In the underlined part 4 , he said that he made friends especially with me because I had been out of China. This means that $M$ views me as one who belongs to the same imagined community of studying abroad. "Need-to-belong can be understood on the basis of a fundamental interpersonal relations orientation, which suggests three basic needs underlie people's group-seeking behavior: inclusion" (Gangadharbatla, 2008). Since I often shared with him what I experienced in Japan as a foreigner, $M$ felt that we were the same kind of person, had similar experience and he thought that I could always understand him. "It is functional for those motivated to forge social bonds (i.e., high in belongingness need) to infer that other potential relationship partners share a similar interest in social connection." (Collisson, 2013, p.513). This shows 
that the need to belong to maintain social relations results from having some points of shared similarity and experience.

From the data I presented, we can see that people build strong social relations through long period interaction motivated by a sense of need to belong involving emotional support or relying and shared experience. Social media provides people with a platform for this relationship build across the time and space.

\section{CONCLUSION}

In this study, I explored learning process and socialization on the social media platforms. Unlike the traditional way of learning, social media platforms provide people with sociotechnical context for sharing, performing, learning and socializing with the people who are from diverse background, which could also facilitate other learning activities, such as face-to face discussion (Bell, 2011). Taking the current education as an example, most schools apply technology as learning materials into teaching and learning process. Online support is rather crucial for critical learning in education (Black et al., 2007). Technology is everywhere, no matter in formal and informal learning. It breaks up the limitation of time and space for people to produce and consume information in the virtual environment. The Internet is the nearest access which has endless amount of information shared and updated by people in different fields all the time. In this case, people could gain knowledge from more knowledgeable others across time and space. It is more flexible to learn online. Learning always happens in the social settings rather than one-side input, which refers to the external converted to internal process. "Informed by a sociocultural perspective, learning is thought to occur through interaction, negotiation, and collaboration" (Scott \& Palincsar, 2013, p. 5). This perspective is also revealed in this research. In the digital age, learning habits are changing so fast and particularly influenced by the interactive Internet environment. Education is perceived as a social process of interactions. Technology provides merit for people to have the rights to choose the contents which they like. This research highlights the informal learning on the social media and relationship construction through the learning process.

Some aspects of learning process and relationship construction have been explored by many researchers, however, in my study, I analyze the learning process occurring on the social media platforms. What information could people observe and share with others? What could be acquired and how learning takes place on the social media. How relationship is constructed through the online learning process? Studies addressing these micro level issues are few.
There are more to explore about online learning and social relations building. I hope I could explore it more in the future study. However, I believe that my study does make contributions to knowledge about learning and socializing online at the micro level.

\section{REFERENCES}

[1] Black, E. W., Beck, D., Dawson, K., Jinks, S., \& DiPietro, M. (2007). Considering implementation and use in the adoption of an LMS in online and blended learning environments. TechTrends, 51(2), 35-53.

[2] Bell, F. (2011). Connectivism: Its place in theory-informed research and innovation in technology-enabled learning. International Review of Research in Open and Distributed Learning, 12(3), 98-118.

[3] Baumeister, R. F., \& Leary, M. R. (1995). The need to belong: desire for interpersonal attachments as a fundamental human motivation. Psychological bulletin, 117(3), 497-529.

[4] Baumeister, R. F. (2011). Need-to-belong theory. In P. A. M. Van Lage, A. W. Kruglanski, \& E. Tory Higgins (Eds.), Handbook of theories of social psychology: volume 2 (pp.121-140). SAGE publications.

[5] Collisson, B. (2013). The Social Projection of Belongingness Needs. North American Journal of Psychology, 15(3), 513526

[6] Fenwick, T., \& Edwards, R. (2010). Actor-network theory in education. Routledge.

[7] Gherardi, S. (2009). Community of practice or practices of a community. In S. J. Armstrong. \& C. V. Fukami.(Eds.), The Sage handbook of management learning, education, and development(pp.514-530). SAGE publications.

[8] Law, J. (2009). Actor network theory and material semiotics. In B.S. Turner (Ed), The new blackwell comparison to social theory, (pp. 141-158). Blackwell.

[9] Leonardi, P. M. (2014). Social media, knowledge sharing, and innovation: Toward a theory of communication visibility. Information systems research, 25(4), 796-816.

[10] Mbati, L. (2013). Online social media applications for constructivism and observational learning. International Review of Research in Open and Distributed Learning, 14(5), 166-185.

[11] Poell, T., De Kloet, J., \& Zeng, G. (2014). Will the real Weibo please stand up? Chinese online contention and actornetwork theory. Chinese Journal of Communication, 7(1), 118.

[12] Scott, S., \& Palincsar, A. (2013). Sociocultural theory. Retrieved February 6,2021, from http://www.education.com/reference/artical/socioculturaltheory/

[13] Vygotsky, L. S. (1978). Mind in society: The development of higher psychological processes. Harvard University Press.

[14] Wegner, D. M., Giuliano, T., \& Hertel, P. T. (1985). Cognitive interdependence in close relationships. In I. William (ed.), Compatible and incompatible relationships (pp. 253-276). Springer. 